UDK: 655.3.022:004.9

DOI: https://doi.org/10.24867/02EF08Bijelic

\title{
ISPITIVANJE POSTOJANOSTI NA PRANJE OTISAKA ODŠTAMPANIH SUBLIMACIONOM ŠTAMPOM
}

\section{RESSISTANCE TESTING FOR WASHABLE PRINTS PRINTED WITH SUBLIMATION PRINTING}

\author{
Željana Bijelić, Nemanja Kašiković, Rastko Milošević, Fakultet tehničkih nauka, Novi Sad
}

\begin{abstract}
Oblast - GRAFIČKO INŽENJERSTVO I DIZAJN
Kratak sadržaj - U okviru rada predstavljena su istraživanja iz oblasti digitalne štampe. Štampanje je vršeno na 3 različite podloge za štampu. Otisak je štampan na transfer papir pomoću "Ricoh SG 3110 DNw" sublimacionog štampača, dok se prenos otiska sa transfer papira na podlogu za štampu vršio pomoću termo prese "Hobby Cut". Istraživanja su zasnovana na skeniranju uzoraka, merenju spektrofotometrijskih vrednosti, pranju uzoraka, a zatim analizi dobijenih rezultata na osnovu kojih je ustanovljena otpornost otiska na pranje u zavisnosti od podloge. U radu je vršena $i$ vizuelna analiza uzoraka.
\end{abstract}

Ključne reči: ink jet štampa, sublimaciona štampa, analiza otisaka, kontrola kvaliteta uzoraka.

\begin{abstract}
The research has been presented in the field of digital printing. Printing was done on 3 different printing media. The color proof has been printed on transfer paper by Ricoh SG $3110 \mathrm{DNw}$ sublimation printer, while the transfer of the printed proof from transfer paper to the print media was done using a Hobby Cut thermal press. The research is based on sample scanning, measurement of spectrophotometric values, washing of samples, and finally the analysis of the obtained results which shows the resistance of the print to washing, depending on the substrate. Furthermore, the thesis also included a visual analysis of the samples.
\end{abstract}

Keywords: ink jet printing, sublimation printing, analysis of prints, quality control of samples.

\section{UVOD}

Ink Jet tehnika spada u digitalnu štampu i predstavlja noviju oblast štamparskih tehnologija i spada u najčešće primenjenu Non Impact tehniku štampe. Oslikavanje kod Ink Jet postupka vrši se direktno na materijal za štampu. To znači da se podaci digitalno opisanog radnog naloga za štampu direktno prenose u upravljački sistem jedinice oslikavanja [1].

Sublimaciona tehnika štampe spada u digitalnu štampu i definiše se kao prelazak supstance iz čvrstog u gasovito agregatno stanje bez tečnog međustanja i u fizici jeste jedan od faznih prelaza.

\section{NAPOMENA:}

Ovaj rad proistekao je iz master rada čiji mentor je bio dr Nemanja Kašiković, van. prof.
Navedena tehnika omogućava primenu sublimacionih boja za različite materijale, uz korišćenje toplotne prese koja pruža zahtevanu kombinaciju: toplote, vreme grejanja (pečenja) i pritiska (ili vakuuma u slučaju različite tehnologije izrade). Ova kombinacija uzrokuje bojama da pređu sa papira iz čvrstog u gasovito agregatno stanje, omogućavajući im da prodru unutar površine nakon čega se formira trajna slika. Boje prodiru $u$ materijal davajući dugotrajan rezultat, visoko obojenje i otpornost na grebanje i pranje [2].

Cilj ovog rada jeste ispitivanje kvaliteta otisaka dobijenih sublimacionom tehnikom štampe nakon pranja uzoraka. Uzorci su tri različite vrste materijala: pamučna majica, sintetička majica, jastučnica od mikrofiber materijala. Zbog ograničenja prostora u nastavku će biti prikazane vrednosti dobijene za pamučnu majicu.

\section{METOD IZVOĐENJA EKSPERIMENTA}

$\mathrm{Na}$ početku eksperimentalnog dela na pomenutim uzorcima odštampana su RGB i CMYK polja veličine 12 x 4 cm. Otisak je štampan na transfer papir pomoću "Ricoh SG 3110 DNw" sublimacionog štampača, dok se prenos otiska sa transfer papira na podlogu za štampu vršio pomoću termo prese "Hobby Cut". Uzorci su prvo skenirani pomoću Canon Scan 5600 f skenera, a zatim su vrednosti LabCh merene pomoću Hp 200 spektrofotometra na svakom od odštampanih polja. Isti postupak je ponovljen nakon prvog, drugog i trećeg pranja.

Pranje je vršeno mašinski, pomoću dodatka pranju (deterdženta) na temperaturi koja odgovara svakom pomenutom uzorku, a to je temperatura $40{ }^{\circ} \mathrm{C}$.

Nakon toga, komentarisane su sve dobijene vrednosti pre i posle pranja. Bitno je utvrditi razliku stanja materijala i otiska pre pranja i nakon svakog sledećeg pranja, kao i faktore koji utiču na promene. Promene su utvrđene objektivnom (pomoću mernog uređaja) i subjektivnom metodom (vizuelnom procenom).

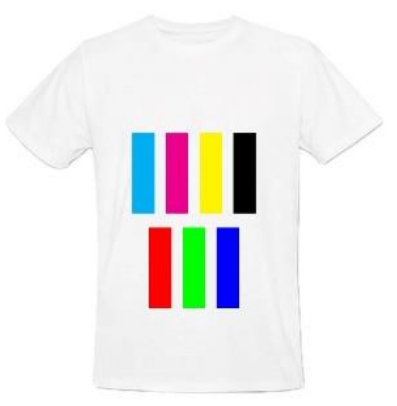

Slika 1. Prikaz majice sa odštampanim otiskom 
Na slici 2 prikazan je izgled uređaja za merenje LabCh vrednosti.

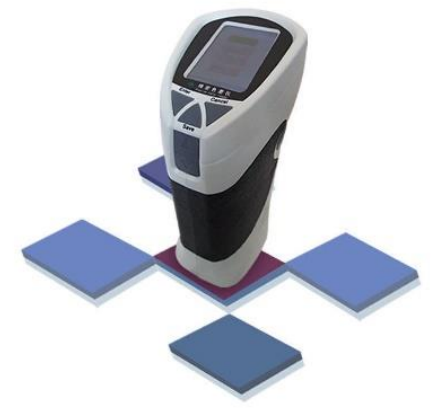

Slika 2. Prikaz Hp 200 spektrofotometra

\section{REZULTATI I DISKUSIJA}

Kao što je rečeno, svaki materijal je izložen dejstvu tri ciklusa pranja. U nastavku ce biti prikazane dobijene vrednosti LabCh kao i razlika boje pre pranja i nakon svakog sledećeg pranja za pamučnu majicu. U pitanju su vrednosti dobijene pomoću pomenutog uređaja prikazanog na slici 2.

U tabelama 1 do 7 prikazane su vrednosti i promene dobijene pre pranja i nakon svakog sledećeg pranja.

Tabela 1 - Vrednosti za cijan na pamučnoj majici

\begin{tabular}{|c|c|c|c|c|}
\hline \multicolumn{5}{|c|}{ Cijan } \\
\hline L pre pranja & 1 pranje & 2 pranje & 3 pranje \\
\hline a & 61,46 & 62,64 & 63,37 & 63,85 \\
\hline b & $-10,42$ & $-9,4,40$ & $-10,23$ & $-9,96$ \\
\hline C & 33,91 & $-36,48$ & $-33,33$ & $-34,34$ \\
\hline h & 252,09 & 255,55 & 25,87 & 35,76 \\
\hline
\end{tabular}

Za vrednosti cijana odštampanog na pamučnoj majici može se zaključiti da su izmerene vrednosti svetline približne, za nijansu veća svetlina zabeležena je nakon trećeg pranja.

Otisak je nakon prvog pranja blago plavlji i zasićeniji.

Tabela 2 - Vrednosti za magentu na pamučnoj majici

\begin{tabular}{|c|c|c|c|c|}
\hline \multicolumn{5}{|c|}{ Magenta } \\
\hline & pre pranja & 1 pranje & 2 pranje & 3 pranje \\
\hline L & 46,15 & 46,28 & 46,01 & 46,45 \\
\hline a & 56,11 & 55,34 & 55,63 & 55,02 \\
\hline b & 4,96 & 3,00 & 4,14 & 2,84 \\
\hline c & 56,33 & 55,42 & 55,65 & 55,10 \\
\hline $\mathrm{h}$ & 5,05 & 3,11 & 4,26 & 2,95 \\
\hline
\end{tabular}

$\mathrm{Za}$ vrednosti magente odštampane na pamučnoj majici može se zaključiti da je svetlina (L) identična pre pranja i nakon tri pranja. Kod parametra "b", vidi se mala razlika pre pranja i nakon tri pranja gde je ton boje postao plavlji. Zasićenost boje je konstantna pre pranja i nakon tri pranja.

Konkretno kod magente na pamučnoj majici nije došlo do velikih i značajnijih promena kada su dobijene vrednosti u pitanju.

Za vrednosti žute, može se primetiti da je svetlina (L) poprilično ujednačena, zaključujemo da je takva situacija kod svake boje koja je odštampana na pamučnoj majici. Razlog može biti i kvalitet prirodnog materijala koji lako upija i lako odpušta vlažnost. Pamučna majica nakon tri pranja kod žute boje pokazuje pri parametrima "a" i "b" da je boja plavlja i zelenija.

\begin{tabular}{|c|c|c|c|c|}
\hline \multicolumn{5}{|c|}{ Zuta } \\
\hline & pre pranja & 1 pranje & 2 pranje & 3 pranje \\
\hline L & 82.58 & 81,80 & 80,89 & 81,21 \\
\hline a & -0.53 & $-2,06$ & $-2,47$ & $-2,31$ \\
\hline b & 59,69 & 54,13 & 52,14 & 51,93 \\
\hline C & 59,71 & 54,17 & 52,20 & 51,98 \\
\hline h & 91,52 & 92,17 & 92,71 & 92,54 \\
\hline
\end{tabular}

Tabela 4 - Vrednosti za crnu na pamučnoj majici

\begin{tabular}{|c|c|c|c|c|}
\hline & \multicolumn{4}{|c|}{ Crna } \\
\hline & pre pranja & 1 pranje & 2 pranje & 3 pranje \\
\hline a & 27,96 & 28,90 & 29,10 & 29,28 \\
\hline b & 2,42 & 2,92 & 3,24 & 2,80 \\
\hline C & $-2,80$ & $-4,97$ & $-3,87$ & $-3,56$ \\
\hline h & 3,70 & 5,77 & 5,05 & 4,53 \\
\hline
\end{tabular}

Za vrednosti crne boje zaključujemo da su približne i da nije došlo do promene na materijalu nakon tri pranja. Objektivna metoda najmerodavnije ukazuje na sve promene koje se dešavaju na materijalu. Boja je za nijansu zasićenija $(\mathrm{C})$ nakon prvog pranja i primećuje se da je za nijansu plavlja nakon prvog pranja. Međutim, pomenuta razlika ne spada u razliku koju je moguće primetiti golim okom, već isključivo pomoću mernog uređaja pomoću kog je i vršeno merenje.

Tabela 5 - Vrednosti za crvenu na pamučnoj majici

\begin{tabular}{|c|c|c|c|c|}
\hline & \multicolumn{5}{|c|}{ Crvena } \\
\hline Lre pranja & 1 pranje & 2 pranje & 3 pranje \\
\hline a & 49,05 & 48,79 & 48,27 & 48,74 \\
\hline b & 72,12 & 69,97 & 69,74 & 69,32 \\
\hline C & 14,88 & 12,34 & 12,75 & 12,61 \\
\hline h & 73,64 & 71,05 & 70,90 & 70,47 \\
\hline
\end{tabular}

Za vrednosti crvene boje svetlina (L) ima približno slične vrednosti. Parametar "a" je nižih vrednosti nakon trećeg pranja i to znači da je boja za nijansu zelenija. Parametar "b" je takođe, nakon trećeg pranja niži nego pre pranja i to znači da je boja plavlja nego pre pranja.

Tabela 6 - Vrednosti za zelenu na pamučnoj majici

\begin{tabular}{|c|c|c|c|c|}
\hline & \multicolumn{5}{|c|}{ Zelena } \\
\hline L & 59,89 & 60,92 & 61,26 & 61,59 \\
\hline a & $-20,75$ & $-20,50$ & $-19,96$ & $-19,86$ \\
\hline b & 26,12 & 22,65 & 22,34 & 21,60 \\
\hline C & 33,37 & 30,56 & 29,96 & 29,35 \\
\hline h & 12,46 & 132,17 & 131,77 & 132,61 \\
\hline
\end{tabular}

Za vrednosti zelene boje na pamučnoj majici zapaža se jedina dominantnija razlika kod parametra "b", gde je boja nakon tri pranja postala plavlja. Najveća zasićenost (C) beleži se kod merenja pre pranja, a najmanja nakon tri pranja. Ostali parametri ne pokazuju bitne razlike pre pranja i nakon tri pranja materijala.

$\mathrm{Za}$ vrednosti plave boje, parametar "L" pokazuje najmanju svetlinu pre pranja materijala, dok nakon pranja materijala svetlina se blago povećava. Parametar "a" je 
nešto veći nakon trećeg pranja i to ukazuje na promenu boje ka crvenijim tonovima. Parametar "b" ukazuje na to da je za nijansu plavlja boja nakon trećeg pranja.

Tabela 7 - Vrednosti za plavu na pamučnoj majici

\begin{tabular}{|c|c|c|c|c|}
\hline & pre pranja & 1 pranje & 2 pranje & 3 pranje \\
\hline L & 32,65 & 35,12 & 35,02 & 35,64 \\
\hline a & 2,50 & 3,22 & 4,04 & 4,35 \\
\hline b & $-23,25$ & $-26,60$ & $-25,94$ & $-25,93$ \\
\hline C & 23,39 & 26,80 & 26,25 & 26,30 \\
\hline h & 276,11 & 276,95 & 278,84 & 279,50 \\
\hline
\end{tabular}

Kako bi se jasnije videla razlika u boji pre pranja i nakon svakog pranja, u nastavku su dati grafici (1 do7).

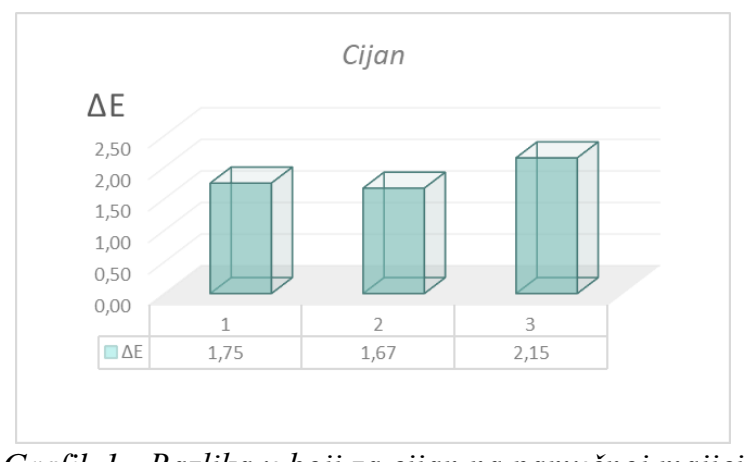

Grafik 1 - Razlika u boji za cijan na pamučnoj majici

Merenjem razlike u boji za cijan odštampan na pamučnoj majici primećuje se mala razlika pri poređenju stanja materijala pre pranja i nakon prvog i drugog pranja. Dok, pri poređenju materijala pre pranja i nakon trećeg pranja dobija se najveći rezultat čija vrednost spada u grupu srednjih razlika koju može primetiti neuvežbano oko.

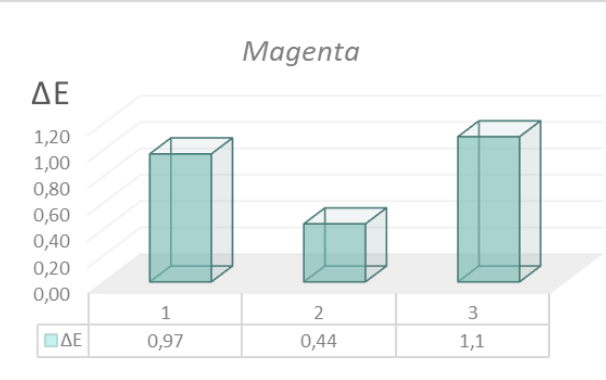

Grafik 2 - Razlika u boji za magentu na pamučnoj majici

Najveća razlika u boji dobijena je pri poređenju materijala pre pranja i nakon trećeg pranja. To je skoro pa neprimetna razlika golim okom. Druge dve dobijene vrednosti spadaju u niske vrednosti i kao razlika boje nisu primetne subjektivnom metodom ocene.

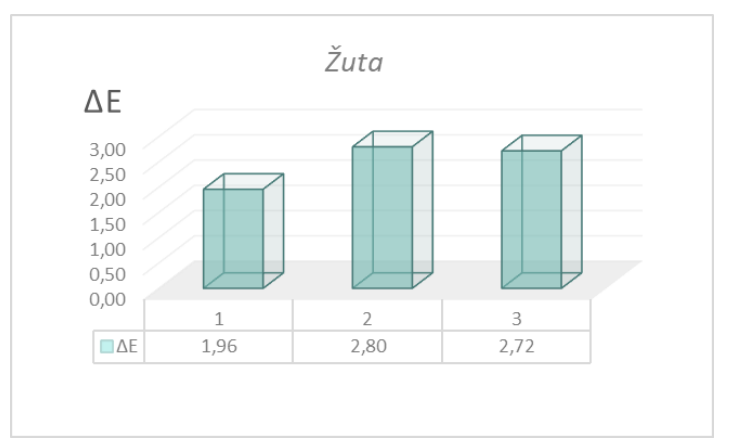

Grafik 3 - Razlika u boji za žutu na pamučnoj majici
Do sada najveće vrednosti razlike u boji prikazane su na grafiku 3. Najmanja razlika zabeležena je nakon prvog pranja, dok je nakon drugog pranja i nakon trećeg pranja razlika u boji porasla. Prikazane razlike spadaju u grupu srednjih razlika, koje može primetiti neuvežbano oko. Ovo je dobar primer u kom nam vrednosti ukazuju na to da pranje utiče na materijal i odštampane otisake, pored niza drugih faktora.

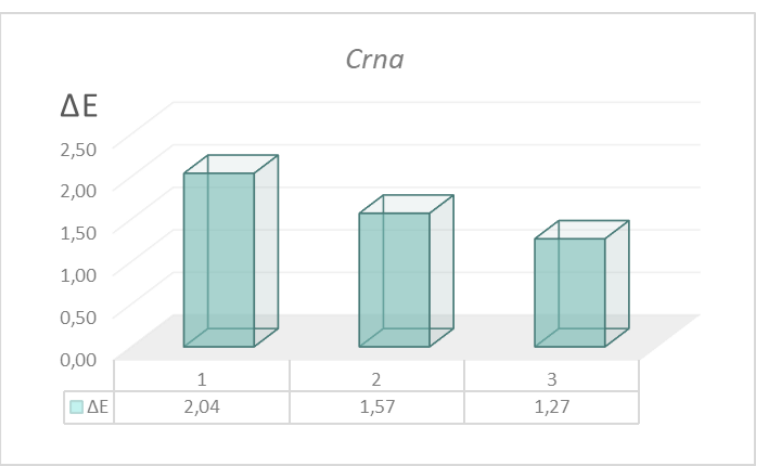

Grafik 4 - Razlika u boji za crnu na pamučnoj majici

Što se tiče crne boje, najveća razlika zabeležena je kod poređenja materijala pre pranja i nakon prvog pranja. Vrednost pre pranja spada u grupu razlika koju bi moglo da primeti i neuvežbano oko.

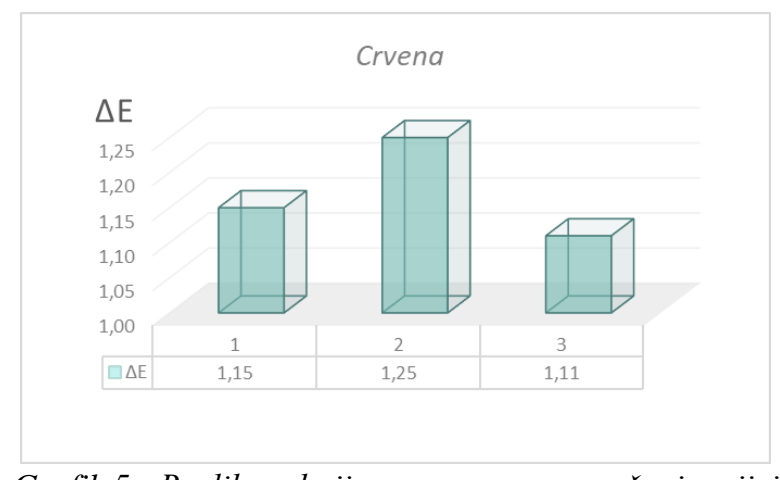

Grafik 5 - Razlika u boji za crvenu na pamučnoj majici

$\mathrm{Na}$ grafiku 5 prikazane vrednosti ukazuju na minimalne promene pri svakom sledećem pranju pamučne majice. Sve vrednosti spadaju u grupu veoma malih razlika i može ih primetiti samo iskusno oko.

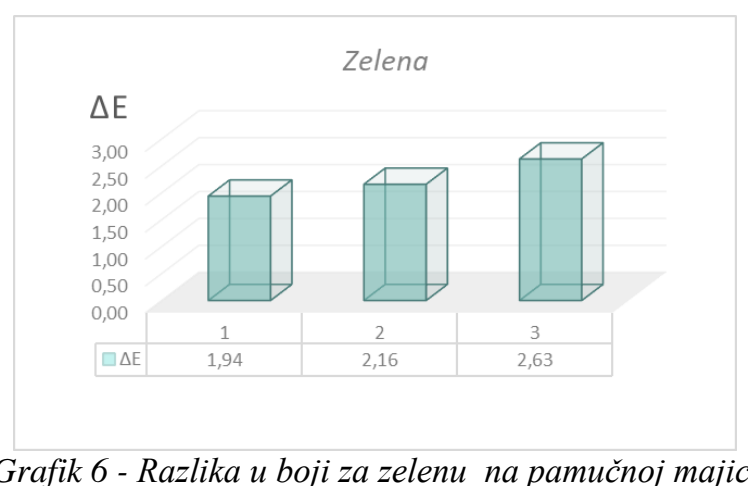

Najveća razlika zabeležena je pri poređenju materijala pre pranja i nakon trećeg pranja.

Data vrednost spada u grupu razlike boje koju može primetiti neuvežbano oko. To nam ukazuje na to da je pranje ove vrste materijala kada je u pitanju zelena boja uticalo na otisak. 
Merenjem otiska plave boje pre pranja i nakon svakog sledećeg pranja dobijene su vrednosti koje jasno ukazuju na to da je došlo do promene boje koja može da se primeti i vizuelnom ocenom razlike u boji. Ovo je dobar primer otiska koji je pikazao promene na materijalu pri poređenju otisaka pre pranja i nakon pranja.

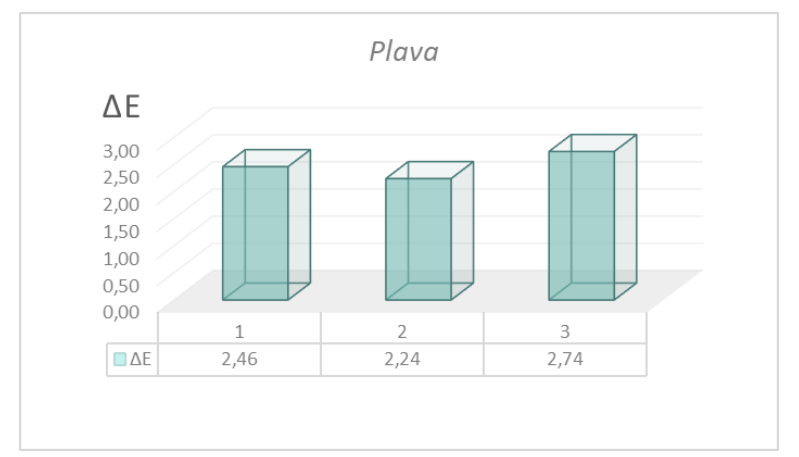

Grafik 7- Razlika u boji za plavu na pamučnoj majici

\section{ZAKLJUČAK}

Štampa je veoma kompleksan proces koji zahteva mnoštvo uslova, znanja, praćenja kontrole kvaliteta otisaka, pedantnost i pored toga zavisi od mnogo faktora. Kako bi radili sa sigurnošću, uvek je najbolje pridržavati se standardima. Postoje razni ISO standardi namenjeni različitim tehnikama štampe, međutim, brzina razvoja tehnologija ponekad ne omogućava momentalno usklađivanje standarda sa novim tehnikama štampe. Uprkos tome, uvek je moguće vršiti kontrolu otisaka prema nekom od referentnih vrednosti koje ocenimo kao prosečan ili optimalan dobijeni otisak.

Objektivna metoda je od svih najmerodavnija jer na najverodostojniji način prikazuje vrednosti. U ovom radu korišćen je spektrofotometar HP 200 sa kojim su se vrednosti beležile u CIELab i CIELCH prostoru boja. CMYK i RGB uzorci su štampani na tri različita materijala, odnosno na pamuku, sintetici i mikrofiber materijalu.

Svaki od korišćenih materijala ima različitu moć upijanja boje, koja se prilikom pranja u većoj ili manjoj meri skida sa tkanine. Tokom procesa pranja mehanički uticaj je, takođe, parametar koji utiče na krajnji utisak o odštampanom otisku.
Rezultati merenja su otkrili da prilikom ispiranja ne dolazi do velikih odstupanja boje sa podloge, te da se sublimaciona štampa pokazala kao dobra i za dugotrajniju upotrebu zbog dobijanja postojanog otiska. Upotreba stabilizatora na pamuku doprinela je dugotrajnijem i čvršćem otisku na pamučnim materijalima.

Ovakvom utisku nisu doprinela samo istraživanja objektivnom metodom - već i subjektivan način procene, kojim je poprilično teško uočiti velike promene. Svaki od 3 navedena materijala (sa CMYK i RGB poljima punog tona) se izlagao pranju po 3 puta, a vrednosti su se beležile pre i nakon svakog od pranja, pri čemu je merena i razlika u boji gde se uporedio odnos pre i nakon svakog od pranja.

Zaključak master rada jeste da je kontrola otisaka neophodna za dobijanje optimalnog otiska, pri čemu to nije sva beneficija. Veća beneficija se ogleda u dobijanju podataka kako treba postupati tokom štampe, kako izbeći nepredviđene okolnosti, te ono najvažnije: steći sigurnost tokom svakog rada u štamparskim procesima.

\section{LITERATURA}

[1] Grid (2018), Nastavni materijal za studente iz tehnika štampe [Online] Dostupno na: http://www.grid.uns.ac.rs/predmet2.html?predmet=66

[2] Mega Electronics (2018), sublimation system education [Online] Dostupno na: https://www.megauk.com/sublimation/sublimation_sy stem_education.php

\section{Adresa za kontakt:}

MSc Željana Bijelić, zeljanabijelic@gmail.com Dr Nemanja Kašiković, knemanja@uns.ac.rs MSc Rastko Milošević, rastko.m@uns.ac.rs 